OPEN ACCESS

Edited by:

Florent Allais,

AgroParisTech Institut des Sciences et Industries du Vivant et de L'environnement, France

Reviewed by:

Tianyi Ma,

University of Newcastle, Australia

Kei Saito,

Monash University, Australia

${ }^{*}$ Correspondence: Rongjun Qu

rongjunqu@sohu.com

Changmei Sun

sunchangmei0535@126.com

Specialty section:

This article was submitted to

Chemical and Process Engineering,

a section of the journal

Frontiers in Chemistry

Received: 11 March 2019

Accepted: 11 June 2019

Published: 02 July 2019

Citation:

Wang Y, Qu R, Mu Y, Sun C, Ji C,

Zhang $Y$, An K, Jia $X$ and

Zhang $Y$ (2019)

Amino- and Thiol- Polysilsesquioxane

Simultaneously Coating on

Poly(p-Phenylenetherephthal Amide)

Fibers: Bifunctional Adsorbents for

Hg(II). Front. Chem. 7:465

doi: 10.3389/fchem.2019.00465

\section{Amino- and Thiol- Polysilsesquioxane Simultaneously Coating on Poly(p-Phenylenetherephthal Amide) Fibers: Bifunctional Adsorbents for Hg(II)}

\author{
Yunfeng Wang, Rongjun Qu*, Yinglei Mu, Changmei Sun*, Chunnuan Ji, Ying Zhang, \\ Kai An, Xinhua Jia and Yu Zhang
}

School of Chemistry and Materials Science, Ludong University, Yantai, China

A double reagents simultaneous functionalization (DRSF) was used to prepare porous polysilsesquioxane with $\mathrm{NH}_{2}$ and $\mathrm{SH}$ bifunctional groups (PAMPSQ) coated poly(p-phenylenetherephthal amide) (PPTA) fibers adsorbents (PPTA-AM), via in situ condensations with aminopropyltriethoxysilane (APTES) and mercaptopropyltriethoxysilane (MPTES). The PAMPSQ coated on the PPTA surface was in the form of nanoparticles and its morphology varied with the proportion of the reactants. The PAMPSQ exhibited loose open meso- or macroporous features. The functional groups utilization of PAMPSQ was much higher than those of polysilsesquioxane on the mono-functional adsorbents with thiol or amino groups. The selective adsorption of PPTA-AM adsorbents for $\mathrm{Hg}(\mathrm{II})$ in binary component metal ion systems indicated their potential application in environmental remediation. The adsorption mechanism of $\mathrm{Hg}(\mathrm{II})$ onto PPTA-AM was proposed.

Keywords: polysilsesquioxane, poly(p-phenylenetherephthal amide), bifunctional adsorbent, adsorption, $\mathrm{Hg}$ (II)

\section{INTRODUCTION}

Water contamination caused by heavy metal ions has become a serious worldwide environmental problem that threatens the ecosystem, food safety, and human health. Thus far, many technologies such as adsorption, solvent extraction, ion exchange, reverse osmosis, membrane filtration, chemical precipitation, and electrolysis have been developed to remove heavy metal ions from contaminated water samples (Huang et al., 1996; Basso et al., 2002; Gomez-Salazar et al., 2003). Among them, adsorption is considered to be the optimum choice because it is facile and highly effective (Zub et al., 2005; Li et al., 2011).

One particular type of adsorbents is based on polysilsesquioxanes, which have desirable properties such as good hydrophilicity, chemical stability, and thermal stability (Hua et al., 2012; Sun et al., 2014). However, there are also unresolved issues regarding easy agglomerate and low utilization rate of the functional groups that eventually limit their applications (Liu et al., 2011). Attempts were made by our group to solve some of these issues. Two types of mono-functionalized fibrous adsorbents were prepared via the sol-gel condensation reactions (Wang et al., 2017). PPTA fibers were separately coated with amino-polysilsesquioxane and thiol-polysilsesquioxane. The resulting adsorbents, denoted as PPTA-A and PPTA-M, respectively, showed enhanced 
adsorption capacity for $\mathrm{Hg}(\mathrm{II})$ as compared to common silica adsorbents and amino- or thiol- functionalized polysilsesquioxane alone, due to the increase in specific surface area and functional group utilization rate. In principle, adsorption capacity of this type of functionalized adsorbents depends on the affinity of the functional group to the metal ion, as well as the morphology of the adsorbent material which affects the functional group utilization rate. PPTA-A is supposed to have similar or slightly better adsorption capacity compared to PPTA-M because of the superior hydrophilicity of the amino group vs. the thiol group. However, PPTA-A exhibited compact gel structures due to existence of lots of hydrogen bond while PPTA-M was able to form loose meso- or macro-porous structures under similar conditions. The overall effect of these two contradicting factors was that the adsorption capacities of PPTA-A samples were much lower than those of PPTA-M ones. It is our assumption that the strong hydrogen bonds between amino groups and PPTA fibers resulted in the compact structures, while the lack of such interaction between thiol groups and PPTA fibers led to the formation of mesoor macro-porous structures. But problems still remain, as the utilization ratio of SH in PPTA-M is unsatisfactory.

In current work, in order to obtain a more ideal adsorbent owning amino and thiol groups at the same time, aminopolysilsesquioxane, and thiol-polysilsesquioxane were introduced onto PPTA by a process named double reagents simultaneous functionalization (DRSF). The combination of weak alkaline amino groups and weak acidic thiol groups, on one hand can reduce the hydrogen bond interactions between the PPTA and functional groups then form porous structures on the surface of PPTA; and introduce simultaneously two kinds of functional groups only via one step on the other. Thus, the adsorbents might enhance $\mathrm{Hg}$ (II) separation effect and the utilization of functional groups. The synthesis proportions of amino groups and thiol groups were optimized. The adsorption kinetics, isotherms, selectivity, and adsorption mechanism of the resulting bi-functionalized adsorbent were investigated and discussed. This novel adsorbent showed favorable pore structures and enhanced adsorption capacities.

\section{EXPERIMENTAL}

\section{Materials and Characterization Methods}

PPTA were provided by Yantai Tayho Advanced Materials Co. Ltd., China. 3-Amino-propyltriethoxysilane (APTES) and 3-mercaptopropyltriethoxysilane (MPTES) were bought from Qufu Wanda Chemical Industry Co. Ltd., China. Dimethylsulfoxide (DMSO) and sodium hydride $(\mathrm{NaH})$ were provided from Kishida Chemicals (Tokyo, Japan). Other reagents and solvents were all of analytical grade and were used as received directly.

Infrared (IR) spectra were measured on a fourier transform infrared (FTIR) spectrophotometer Nicolet iS50 (Nicolet, American). Surface morphologies were examined using Field Emission Scanning Electron Microscope (FE-SEM SU8010) (Hitachi, Japan). Thermogravimetric analysis (TGA) was analyzed on a TA instrument for thermogravimetric analysis
(NETZSCHSTA 409 thermal analyzer, Germany). Elemental analysis was obtained using an Elementar Vario EL b model elemental analyzer (Elementar, Germany). Wide-angle X-ray diffraction (WAXD) curves were carried out on a RigakuD/max-2500VPC (Japan). X-ray photoelectron spectroscopy (XPS) was performed on ESCALAB $\mathrm{Xi}^{+}$(Thermo Fisher Scientific, American). The parameters of the porous structures were determined using an automatic physisorption analyzer (ASAP 2020, Micromeritics, USA). Analysis of various metal ions was performed on a flame atomic absorption spectrophotometer (Varian AA240, American). The contents of $-\mathrm{NH}_{2}$ and $-\mathrm{SH}$ groups were determined by elemental analysis.

\section{Preparation of PPTA-AM}

Preparation of PPTA-ECH and PPTA-APTES followed the method in our previous work (Xu et al., 2016; Wang et al., 2017). Then different molar ratios of APTES and MPTES (see Table 1) were dissolved in $150 \mathrm{~mL}$ DMSO and added to PPTAAPTES in the flask. The mixture was subsequently stirred at $60^{\circ} \mathrm{C}$ for $12 \mathrm{~h}$ and was cooled to room temperature. $\mathrm{NH}_{4} \mathrm{~F}$ of $4 \mathrm{~mL}\left(0.014 \mathrm{~g} \mathrm{~mL}^{-1}\right)$ was added gradually with stirring and the resulting mixture was stirred for an additional $24 \mathrm{~h}$. Solid fibers and solution were then poured into a Teflon-lined reactor and let to stand for 7 days, maintained at a near-constant temperature of $80^{\circ} \mathrm{C}$. Finally, the resulted fibers were separated from the solution, extracted using re-fluxing ethanol for $48 \mathrm{~h}$ and dried under vacuum at $60^{\circ} \mathrm{C}$ for $80 \mathrm{~h}$. The final products were denoted as PPTA-AM-n as shown in Table $\mathbf{1}$, where $\mathrm{n}$ corresponds to the percentage of APTES added. The synthetic route for the preparation of PPTA-AM samples is illustrated in Scheme $\mathbf{1 .}$

\section{Adsorption Experiments}

The adsorption experiments were carried out using $20 \mathrm{~mL}$ of different concentrations of $\mathrm{Hg}$ (II) solution with predetermined amounts of PPTA-AM. The mixture solution was shaken at $25^{\circ} \mathrm{C}$ and $\mathrm{pH} 5.0$ for $24 \mathrm{~h}$. The equilibrium concentration of each solution was measured by Varian AA240. The adsorption capacity of $\mathrm{Hg}$ (II) was calculated according to Equation (1):

$$
q_{e}=\frac{\left(C_{0}-C\right) V}{W}
$$

where $q_{\mathrm{e}}$ represents the adsorption amount $\left(\mathrm{mmol} \mathrm{g}^{-1}\right) ; C_{0}$ and $\mathrm{C}$ represent the initial and final concentrations, respectively $\left(\mathrm{mmol} \mathrm{mL} \mathrm{L}^{-1}\right) ; V$, the volume of solution $(\mathrm{mL}) ; W$, the weight of adsorbents ( $\mathrm{g}$ ).

Adsorption kinetics were investigated from 0 to $7 \mathrm{~h}$ and the amount of adsorbent used was $20 \mathrm{mg}$. In addition, the effect of $\mathrm{Hg}$ (II) initial concentration was also studied. The initial concentrations were varied from 1 to $5 \mathrm{mmol} \mathrm{L}^{-1}$ at $25^{\circ} \mathrm{C}$.

Adsorption selectivity of PPTA-AM-n was established by analyzing a solution containing $\mathrm{Hg}(\mathrm{II})$ and a coexisting ion including $\mathrm{Cu}(\mathrm{II}), \mathrm{Ni}(\mathrm{II}), \mathrm{Pb}(\mathrm{II}), \mathrm{Ag}(\mathrm{I})$, and $\mathrm{Cd}(\mathrm{II})$. The used adsorbents, PPTA-AM-n with adsorbed $\mathrm{Hg}$ (II), were eluted using different percentages $(0,1,2,3,4$, and $5 \%)$ of thiourea in $0.5 \mathrm{M} \mathrm{HCl}$. The most effective eluent of $4 \%$ thiourea in $0.5 \mathrm{M}$ $\mathrm{HCl}$ was used in five adsorption-desorption cycles on each adsorbent sample. 
TABLE 1 | Formulations, element concentrations and binding energies of $\mathrm{N}_{1 \mathrm{~s}}, \mathrm{~S}_{2 \mathrm{p}}$, and $\mathrm{Si}_{2 \mathrm{P}}$ of PPTA and PPTA-AM samples.

\begin{tabular}{|c|c|c|c|c|c|c|c|c|}
\hline \multirow[t]{2}{*}{ Samples } & \multirow{2}{*}{$\begin{array}{l}\text { APTES (mol)/ } \\
\text { MPTES (mol) } \\
\text { (Molar ratio) }\end{array}$} & \multicolumn{5}{|c|}{$\begin{array}{c}\text { Element concentrations } \\
\text { Atomic } \%\end{array}$} & \multicolumn{2}{|c|}{$\begin{array}{l}\text { Functional groups } \\
\text { content }\left(\mathrm{mmol} \mathrm{g}^{-1}\right)\end{array}$} \\
\hline & & $\mathrm{C}_{1 \mathrm{~S}}$ & $\mathrm{~N}_{1 \mathrm{~S}}$ & $\mathrm{o}_{1 \mathrm{~S}}$ & $\mathrm{Si}_{2 \mathrm{P}}$ & $\mathrm{S}_{2 \mathrm{P}}$ & $\mathrm{NH}_{2}$ & SH \\
\hline PPTA & $0 / 0$ & 73.68 & 7.85 & 19.47 & & & & \\
\hline PPTA-AM-90 & $136.17 / 15.13(9 / 1)$ & 67.14 & 6.07 & 16.37 & 8.63 & 1.79 & 1.25 & 0.55 \\
\hline PPTA-AM-70 & $105.91 / 45.39(7 / 3)$ & 58.26 & 5.94 & 19.52 & 11.91 & 4.37 & 0.95 & 0.97 \\
\hline PPTA-AM-10 & $15.13 / 136.17(1 / 9)$ & 51.75 & 5.06 & 22.16 & 13.19 & 7.84 & 0.13 & 1.75 \\
\hline
\end{tabular}

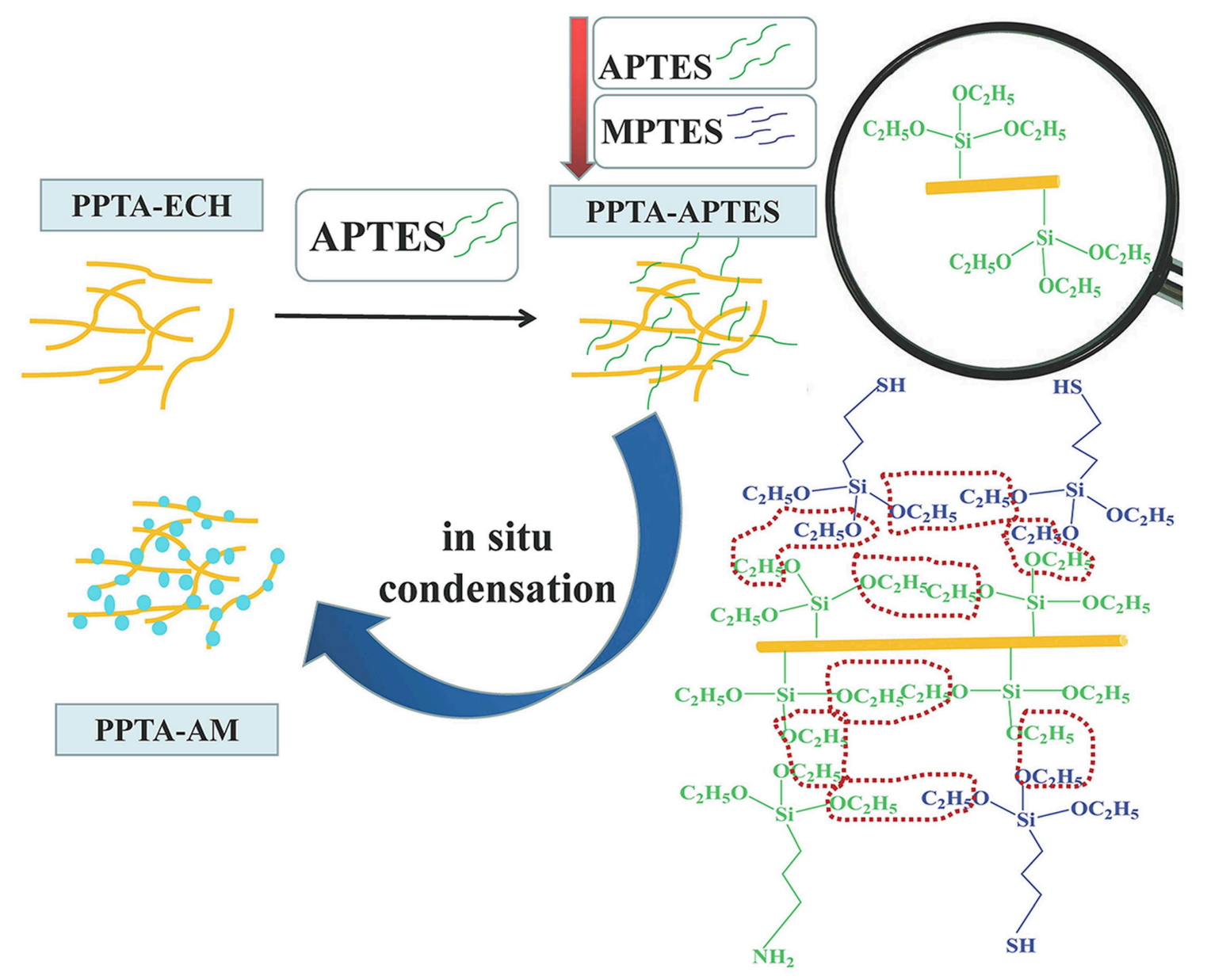

SCHEME 1 | Schematic diagram of the simultaneous functionalization process for PPTA-AM.

\section{RESULTS AND DISCUSSION}

\section{Characterization of PPTA-AM}

IR Spectroscopy Analysis

The IR spectra of PPTA-AM samples are presented in Figure 1. It can be observed that the absorption peaks around 1,640 and 1,545 $\mathrm{cm}^{-1}$ in PPTA fiber, which correspond to the $\mathrm{C}=\mathrm{O}$ stretching vibration of amide and $\mathrm{C}-\mathrm{N}$ stretching vibration, respectively (Yang et al., 2011), were weakened after modifications and appeared red-shifted in PPTA-AM samples. The peak at 1,574 $\mathrm{cm}^{-1}$ attributed to the in-plane bending vibration absorption of - $\mathrm{NH}_{2}$ (from APTES) (Mehdipouratae et al., 2013) was present in PPTA-PAPSQ (Wang et al., 2017) but absent in all PPTAAM samples. This may be due to the interactions between the thiol groups in MPTES and the amino groups in APTES. Two broad and strong absorption peaks around 1,104 and $1,010 \mathrm{~cm}^{-1}$ in PPPTA-AM samples as compared to one intense absorption peak at about $1,130 \mathrm{~cm}^{-1}$ in both PPTA-A and PPTA-M samples, 


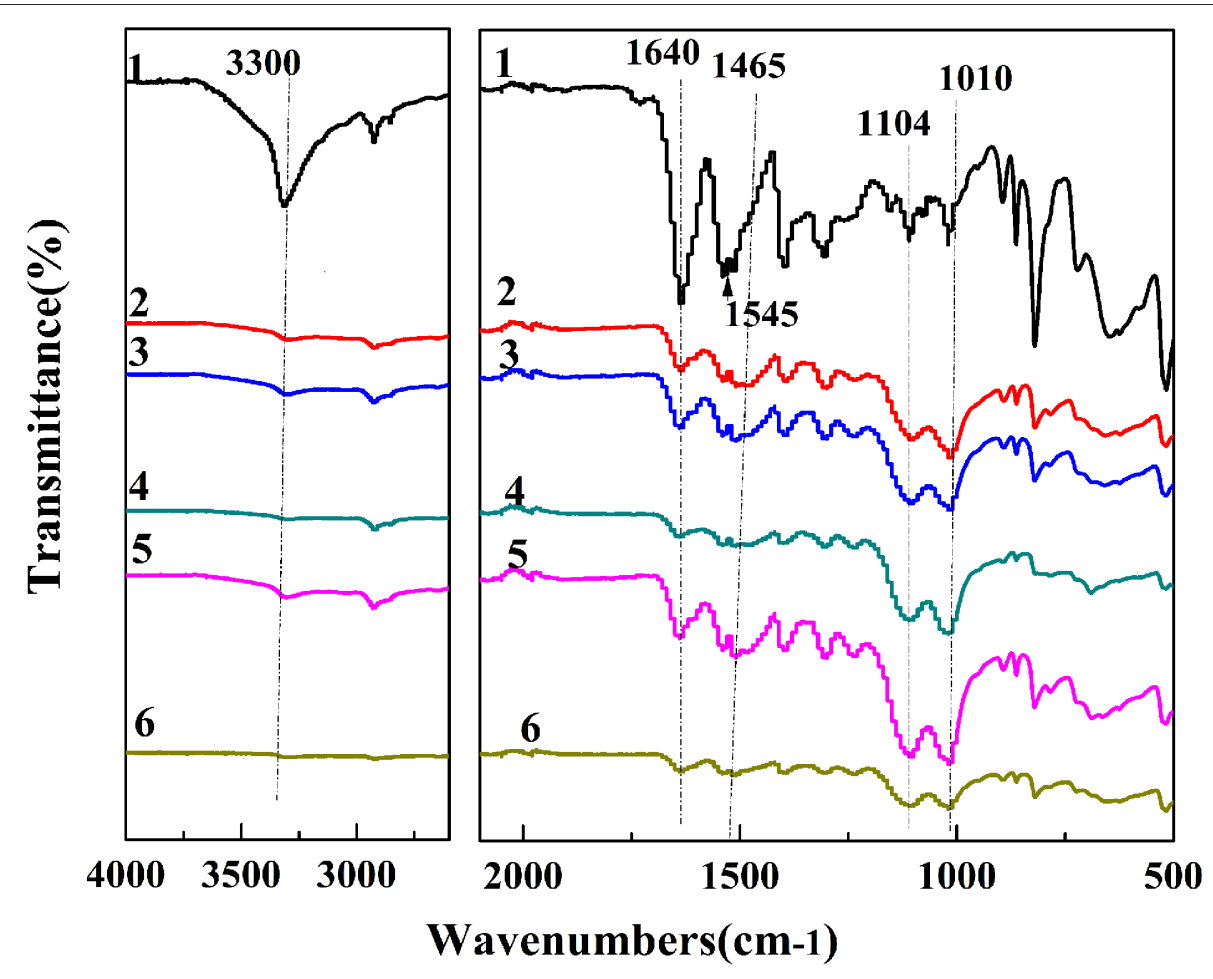

FIGURE 1 | IR spectra of PPTA and PPTA-AM samples. PPTA (1), PPTA-AM-90 (2), PPTA-AM-70 (3), PPTA-AM-50 (4), PPTA-AM-30 (5), and PPTA-AM-10 (6).

which can be attributed to -Si-O-Si- structure (Wang et al., 2017). This indicated that the structures of polysilsesquioxane with bifunctional groups of thiol- and amino- in PPTA-AM samples were different from those in mono-functional PPTA-A and PPTA-M adsorbents.

\section{FE-SEM Images}

As shown in Figure 2, PPTA-AM samples coated with various amounts of polysilsesquioxane exhibited varied surface morphologies. PPTA-AM-90 possessed a compact porous surface coating, and the surface nanoparticles of polysilsesquioxane (NPPSQ) were tightly cemented together. Conversely, there were a large number of NPPSQs densely aggregated in the form of "pearl chains" on the surface of PPTA-AM-70. The NPPSQs were relatively evenly distributed on the surface of PPTA-AM-50 and PPTA-AM-30, but severely agglomerated on the surface of PPTA-AM-10. The above observations indicated that the ratio of APTES and MPTES had important effects on the morphology and structures of NPPSQs on the surface PPTA-AM samples. When the proportion of APTES was higher than that of MPTES, NPPSQs tended to form compact porous structures shown on PPTA-AM-90 and PPTA-AM-70, which was due to the hydrogen-bonding interaction of $-\mathrm{NH}_{2}$ in APTES (Wang et al., 2017). When the proportion of APTES were equal to (in the cases of PPTA-AM-50) or lower than that of MPTES (in the cases of PPTA-AM-30 and PPTA-AM-10), NPPSQs tended to form loose and porous structures because of the weakened hydrogen-bonding interaction of $-\mathrm{NH}_{2}$ caused by its interaction with -SH in MPTES.

\section{XPS Analysis}

XPS results of wide-scan spectra of PPTA and PPTA-AM are shown in Figure 3. The element concentrations (Table 1) of $\mathrm{N}$ showed a gradually decreasing trend while those of $\mathrm{S}$ showed a gradually increasing trend. However, the ratio of $\mathrm{N}$ to $\mathrm{S}$ on the surface of PPTA-AM was not the same as that in the reactant mixture of APTES and MPTES. The binding energies of $\mathrm{N}_{1 \mathrm{~s}}$ showed three peaks of $\mathrm{N}_{1 \mathrm{~S}}$ in PPTA-AM-90-PPTA-AM-30 that appeared at about 399, 400, and $401 \mathrm{eV}$, which can be assigned to $\mathrm{NH}_{2}$ (Metwalli et al., 2006; Majumder et al., 2009), amide (Giordani et al., 2009), and the protonated $\mathrm{NH}_{2}$ adjacent to $\mathrm{Si}$ $\mathrm{OH}$, respectively (Acres et al., 2012). The binding energies of $\mathrm{Si}_{2 \mathrm{p}}$ that appeared at about 102 and $103 \mathrm{eV}$ indicated there were two types of $\mathrm{Si}$ in the polysilsesquioxane structure, which could be assigned to $\mathrm{Si}-\mathrm{O}-\mathrm{Si}$ and $\mathrm{Si}-\mathrm{OH}$, respectively (Kropman et al., 1997; Qiao et al., 2015). But in the spectrum of PPTA-AM-10, only one peak of $\mathrm{Si}_{2 \mathrm{p}}$ appeared at $102.45 \mathrm{eV}$, which was attributed to $\mathrm{Si}-\mathrm{O}-\mathrm{Si}$ due to the highest MPTES proportion. It should be noted that the binding energy of $\mathrm{S}_{2 \mathrm{P}}$ increased gradually from PPTA-AM-90 to PPTA-AM-10 due to the interaction between $\mathrm{SH}$ and $\mathrm{NH}_{2}$, indicating that the ratio of APTES and MPTES may have contributed to the difference of polysilsesquioxane structure in the PPTA-AM surface.

\section{XRD Analysis and Nitrogen Adsorption Measurements}

The WAXD patterns of PPTA and PPTA-AM samples and their corresponding crystalline parameters are presented in Figure 4 and Table 2, respectively. As shown in Table 2, the Bragg angle 

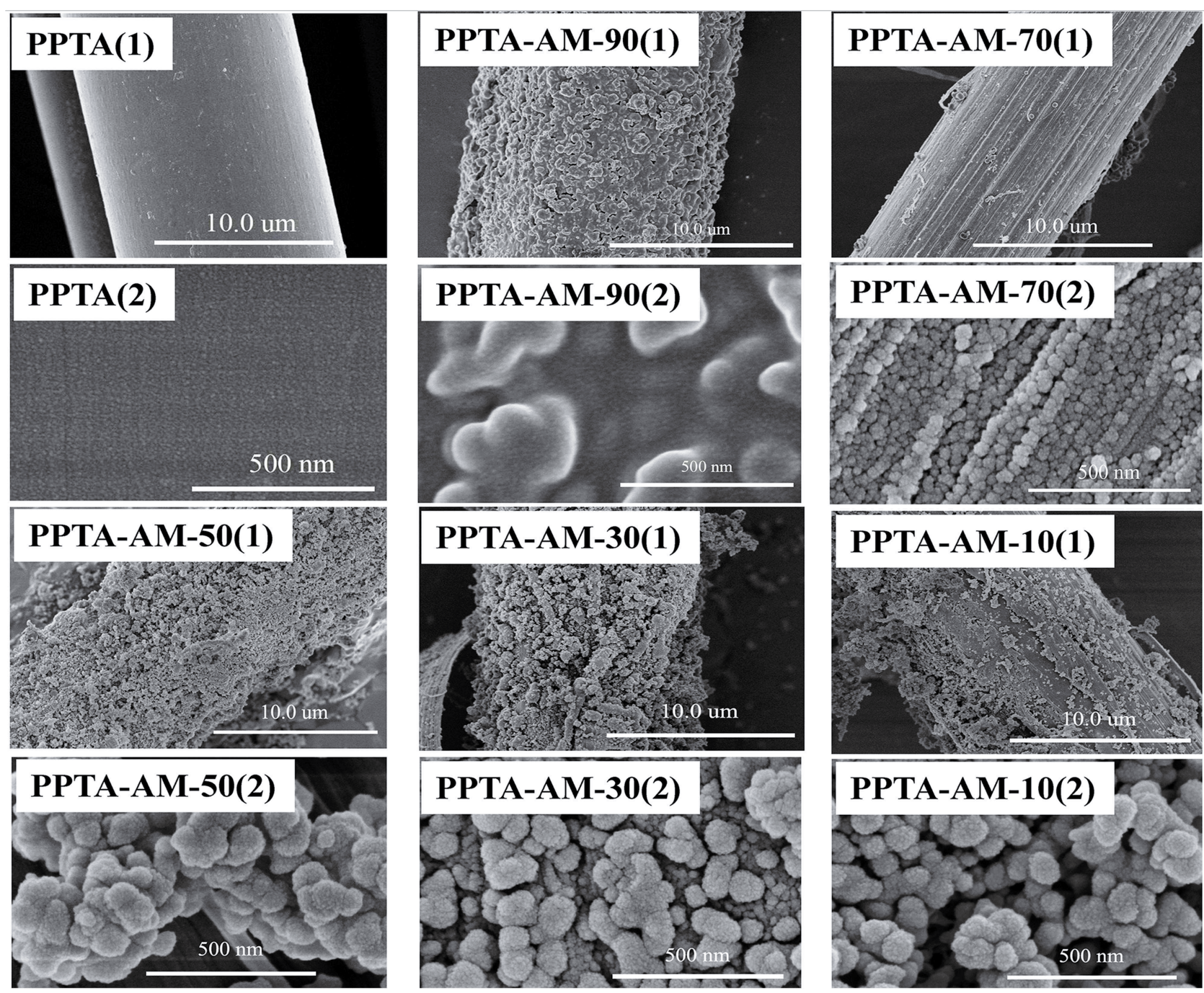

FIGURE 2 | FE-SEM images of PPTA and PPTA-AM samples.

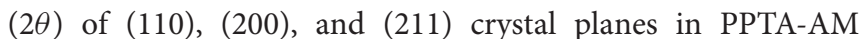
samples, slightly decreased compared with those of PPTA fibers, implying that the inter-planar spacing of each plane increased and the stacking density of the crystallite decreased (Zhang et al., 2006). Meanwhile, the values of full-width at half maximum (fwhm) and the average sizes of crystallites perpendicular to their diffracting planes $\left(\mathrm{L}_{\mathrm{hkl}}\right)$ of modified PPTA fibers (PPTA$\mathrm{AM})$ slightly increased. All the results suggested that the crystal structures of PPTA fibers were affected significantly after modifications, so that their relative crystallinity (crystalline index, CI) was decreased. The CI of PPTA-AM samples were lower than those of PPTA-A and closer to those of PPTA-M. This may be due to the weakened effect of $\mathrm{NH}_{2}$ on the crystal structure of PPTA fibers caused by the interaction between $\mathrm{NH}_{2}$ and $\mathrm{SH}$. Similarly to findings in our previous work, the intensities of the diffraction peaks at 20.5 and $22.6^{\circ}$ in PPTAAM samples decreased compared with those of the PPTA fibers. This indicated the amorphous structures of polysilsesquioxane with thiol and amino of bifunctional groups on the surface of PPTA-AM (Li et al., 2015).

\section{Nitrogen Adsorption Measurements}

Results from the nitrogen adsorption-desorption experiments are shown in Figure 5. It can be seen that the curves of nitrogen adsorption -desorption isotherms PPTA-AM samples were classified as type IV with $\mathrm{H} 3$ type hysteresis loop according to the IUPAC classification (Zhao et al., 2012), suggesting that PPTA-AM samples contained meso- or macroporous structures. The hysteresis loops of all the PPTA-AM samples extrapolated almost to $\mathrm{P} / \mathrm{P} 0=1$, suggesting complete filling of the mesopores (Adam et al., 2010), which is also regarded as one of the characteristics of solids consisting of aggregates or agglomerate particles forming slit-shaped pores with non-uniform size and shape (Ahmed and Adam, 2007).

Table 2 showed that the $\mathrm{BJH}$ desorption pore size distributions of PPTA-AM-90-PPTA-AM-10 were 


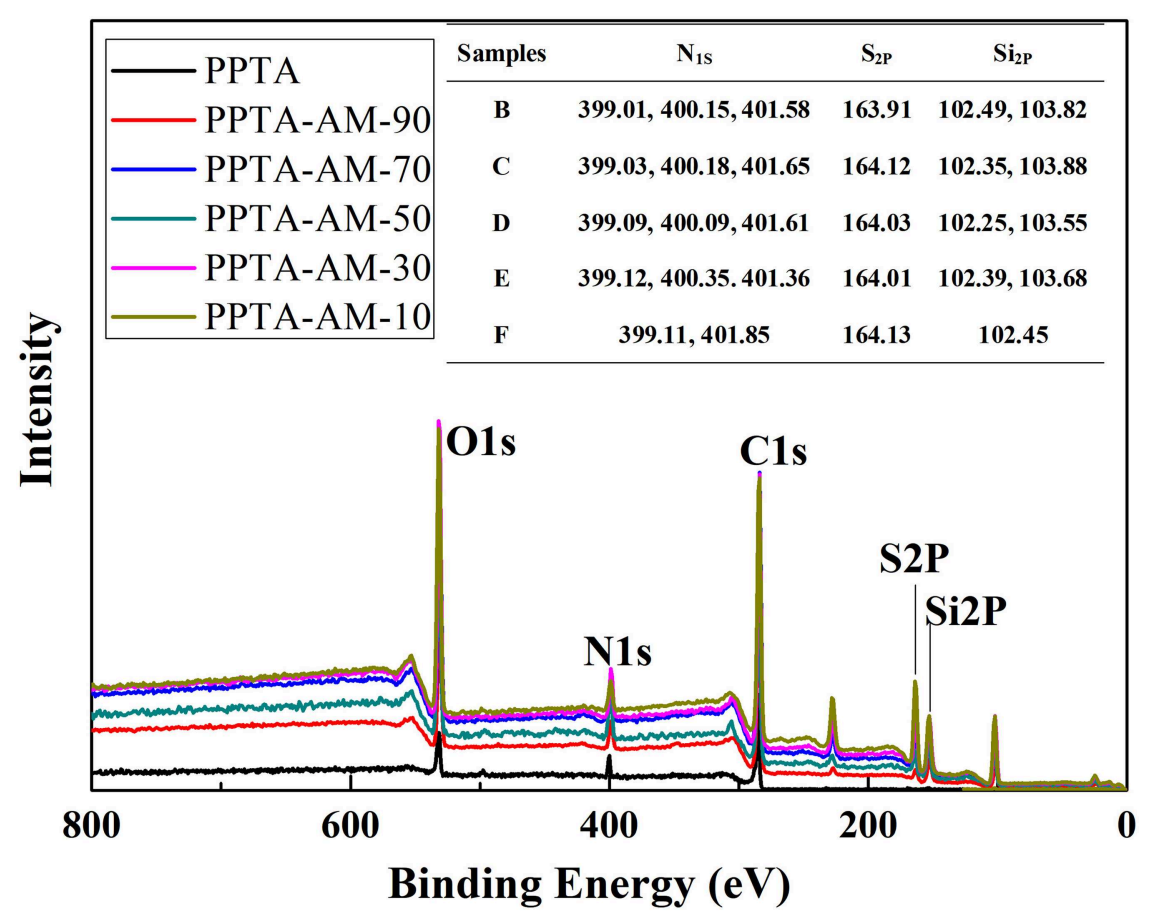

FIGURE 3 | XPS spectra of PPTA and PPTA-AM samples.

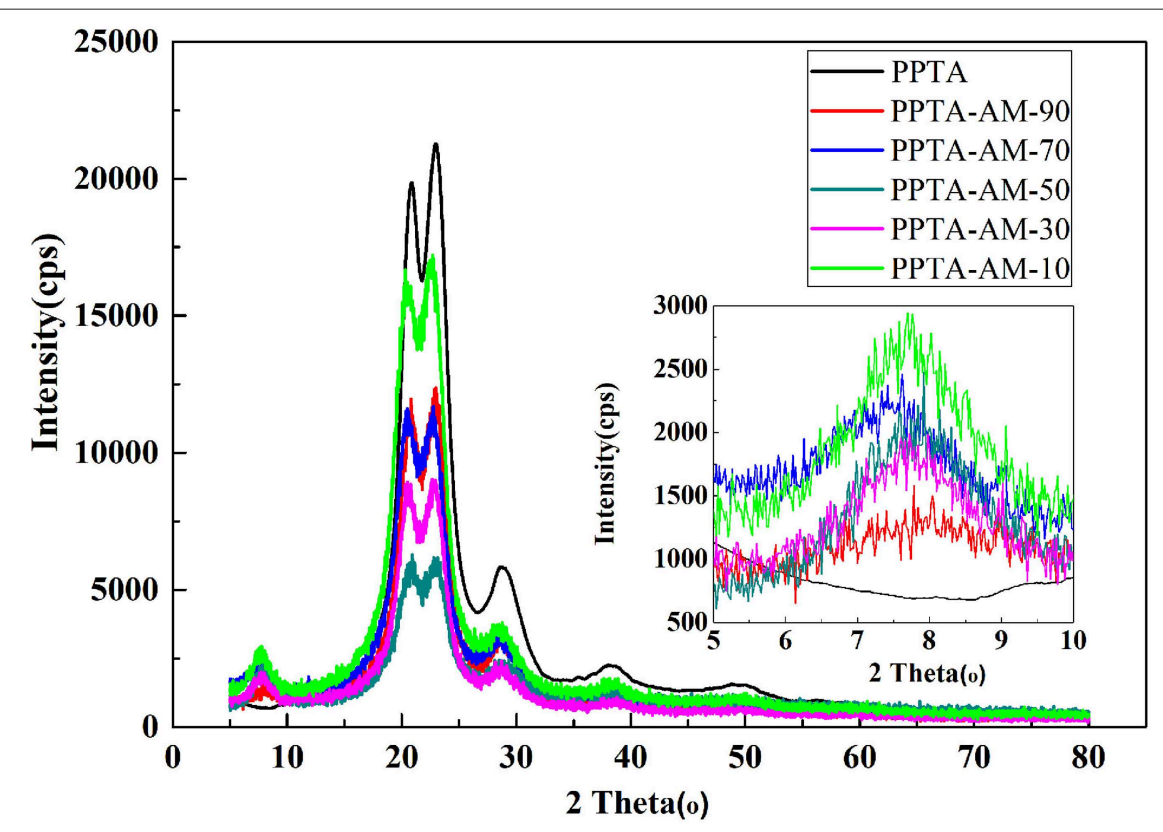

FIGURE 4 | XRD patterns of PPTA and PPTA-AM samples.

predominately in the ranges of $10 \sim 85,5 \sim 80,5 \sim 60,1 \sim 65$, and $1 \sim 70 \mathrm{~nm}$, respectively, which were slightly lower than that of PPTA- M (5-107 nm). The above results demonstrated that the adsorbents with porous structures can be obtained by using the DRSF method.

\section{Saturated Adsorption}

The saturated adsorption capacities of PPTA-AM for $\mathrm{Hg}$ (II) are presented in Figure 6A. For PPTA-A obtained using different quantity of APTES, the amounts of $\mathrm{NH}_{2}$ are $0.63,0.99,1.31$, 1.51, and 1.52, and the adsorption amounts are 0.07, 0.20, 
TABLE 2 | Formulations, element concentrations, parameters of porous structures and ratio of functional group to metal ionon the surfaces of PPTA and PPTA-AM samples.

\begin{tabular}{|c|c|c|c|c|c|c|c|c|c|c|c|c|c|}
\hline \multirow[t]{2}{*}{ Samples } & \multirow{2}{*}{$\begin{array}{c}\text { BET surface } \\
\text { area }\left(\mathrm{m}^{2} \mathrm{~g}^{-1}\right)\end{array}$} & \multirow{2}{*}{$\begin{array}{l}\text { BJH desorption } \\
\text { cumulative pore } \\
\text { volume }\left(\mathrm{cm}^{3} \mathrm{~g}^{-1}\right)\end{array}$} & \multirow{2}{*}{$\begin{array}{l}\text { BJH desorption } \\
\text { pore diameter } \\
(\mathrm{nm})\end{array}$} & \multicolumn{3}{|c|}{$2 \theta\left(^{\circ}\right)$} & \multicolumn{3}{|c|}{ fwhm $\left({ }^{\circ}\right)$} & \multicolumn{3}{|c|}{$L_{h k l}(n m)$} & \multirow[t]{2}{*}{$\mathrm{Cl}(\%)$} \\
\hline & & & & (110) & (200) & (211) & (110) & (200) & (211) & (110) & (200) & (211) & \\
\hline PPTA & - & - & - & 20.89 & 22.98 & 28.76 & 2.38 & 2.06 & 2.48 & 4.26 & 3.86 & 3.10 & 82.06 \\
\hline PPTA-AM-90 & 2.04 & 0.03 & $10 \sim 85$ & 20.83 & 22.95 & 28.64 & 2.49 & 2.11 & 2.52 & 4.31 & 3.88 & 3.12 & 75.58 \\
\hline PPTA-AM-70 & 6.57 & 0.04 & $5 \sim 80$ & 20.79 & 22.96 & 28.61 & 2.53 & 2.12 & 2.54 & 4.35 & 3.87 & 3.13 & 74.89 \\
\hline PPTA-AM-50 & 7.16 & 0.15 & $1 \sim 60$ & 20.80 & 22.96 & 28.65 & 2.51 & 2.05 & 2.57 & 4.30 & 3.86 & 3.11 & 71.14 \\
\hline
\end{tabular}

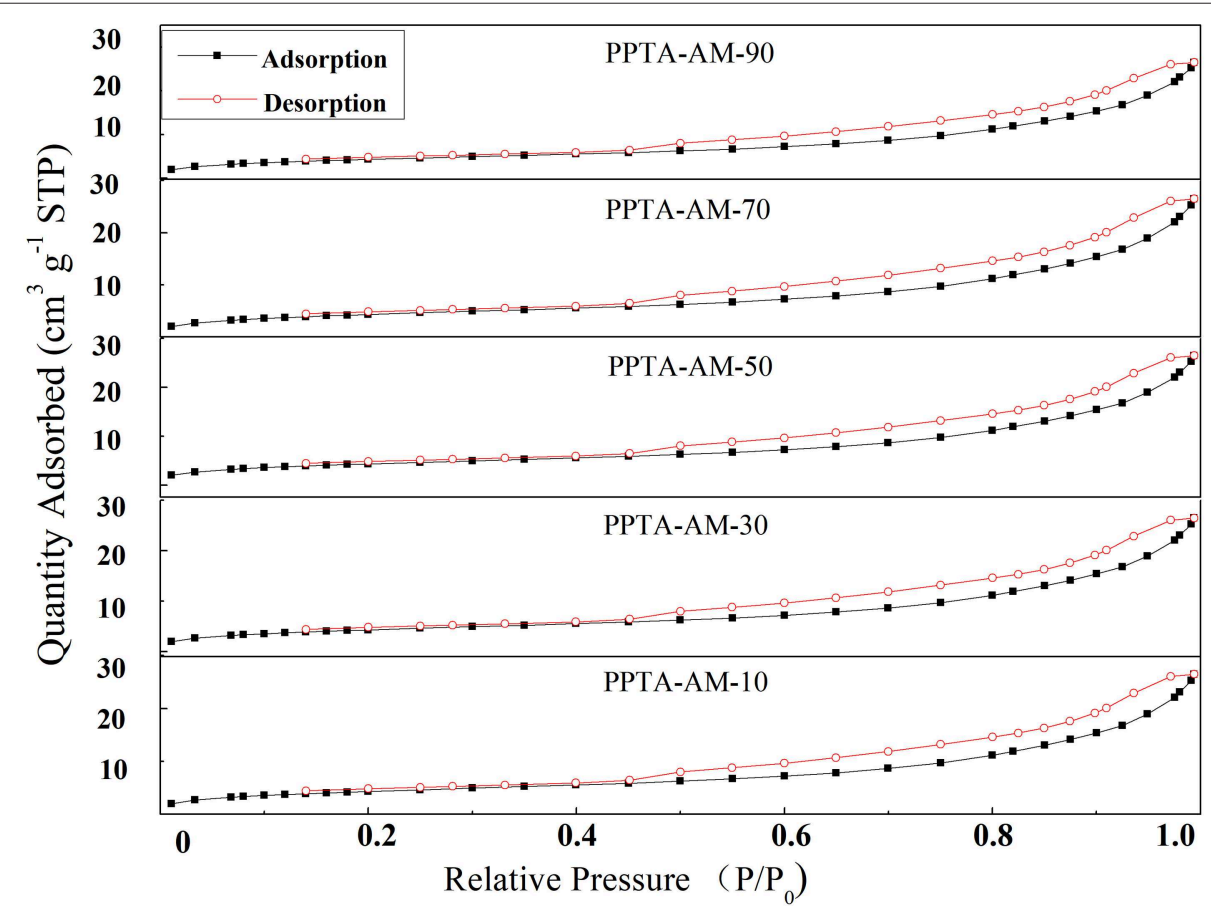

FIGURE 5 | Nitrogen adsorption-desorption isotherms of PPTA-AM samples.

$0.26,0.28$, and $0.28 \mathrm{mmol}^{-1}$. And for PPTA-M obtained using different quantity of MPTES, the amounts of $\mathrm{SH}$ are $1.41,2.04,2.18,3.45$, and $3.51 \mathrm{mmol} \mathrm{g}^{-1}$, and the adsorption amounts are $0.32,0.58,0.65,0.78$, and $0.78 \mathrm{mmol} \mathrm{g}^{-1}$. As shown in Figure 6A, the saturated adsorption capacities of PPTA-AM-90-PPTA-AM-10 for $\mathrm{Hg}$ (II) were $1.13,1.36,1.32$, 1.22 , and $1.19 \mathrm{mmol} \mathrm{g}^{-1}$, respectively. That is, anyone is much higher than that adsorption maximum of PPTA-A $(0.28 \mathrm{mmol}$ $\mathrm{g}^{-1}$, with the highest amount of $\mathrm{NH}_{2}$ is $1.52 \mathrm{mmol} \mathrm{g}^{-1}$ ) and that adsorption maximum of PPTA-M $\left(0.78 \mathrm{mmol} \mathrm{g}^{-1}\right.$, with the highest amount of $\mathrm{SH}$ is $3.51 \mathrm{mmol} \mathrm{g}^{-1}$ ). Obviously, the adsorption effect of amino- and thiol- polysilsesquioxane simultaneously coating on poly( $p$-phenylenetherephthal amide) fibers were much better than mono-functionalized poly(pphenylenetherephthal amide) fibers (PPTA-A and PPTA-M) befitting from the synergistic effect. The adsorption capacity of PPTA-A was lower than those of PPTA-AM, which could be attributed to the lower loading of polysilsesquioxanes coating on the surface. The only explanation for the much higher adsorption capacities of PPTA-AM is that the polysilsesquioxanes with bifunctional groups in PPTA-AM samples were of different form and more conducive to $\mathrm{Hg}$ (II) adsorption than those in PPTA-M. Meanwhile, the $\mathrm{Hg}(\mathrm{II})$ adsorption capacities of PPTAAM followed the descending order of PPTA-AM-70, PPTAAMPPTA-AM-50, PPTA-AM-90, PPTA-AM-30, and PPTA-AM10. This may be caused by a variety of factors such as the content of functional groups, pore structure and morphology of polysilsesquioxanes coating.

\section{Determination of the Optimum pH Value}

The $\mathrm{pH}$ value of the metal ions solution can impact the interaction between metal ions and the surface structure of adsorbents. The relationship between the saturated adsorption capacities and $\mathrm{pH}$ is shown in Figure 6B. It was found that 

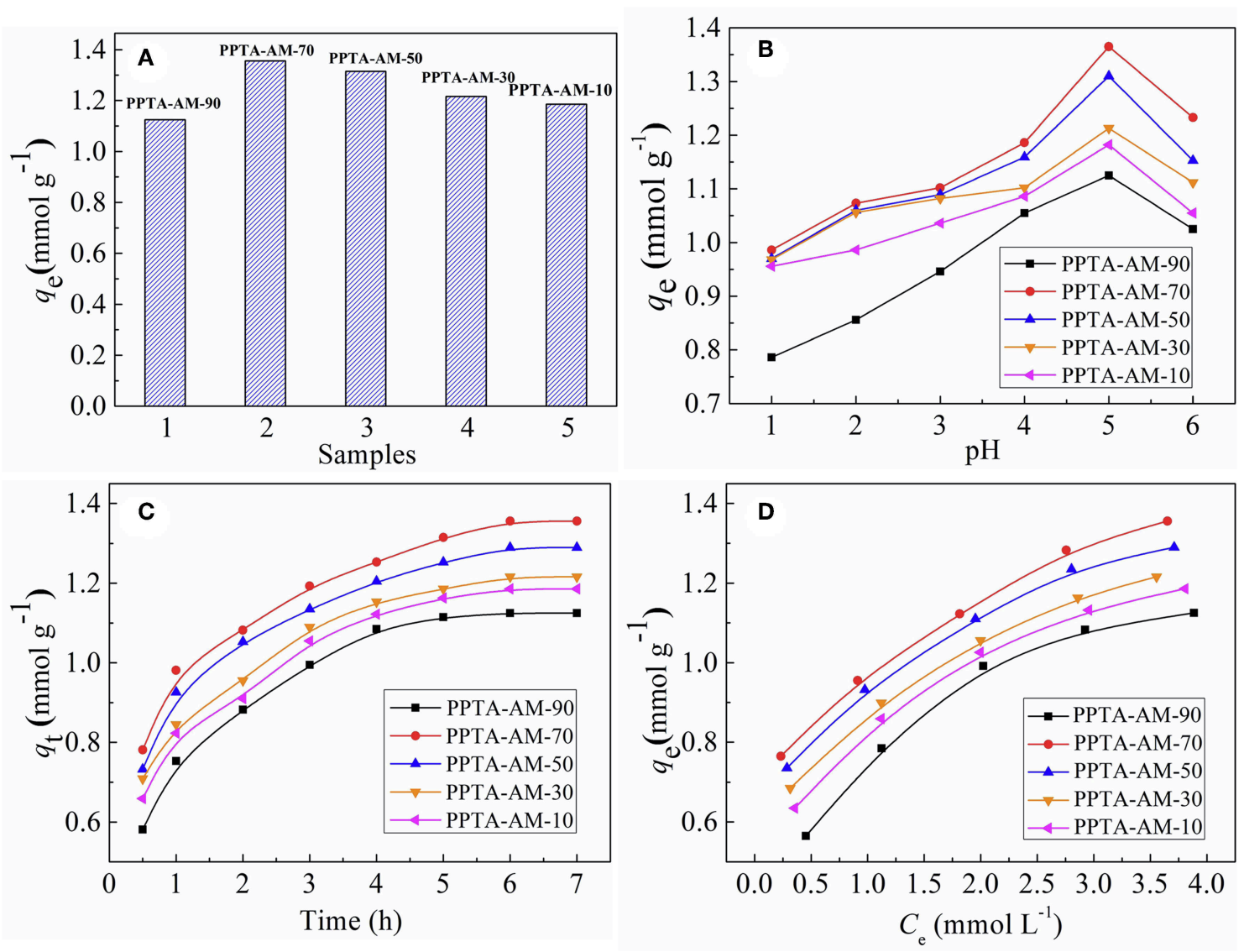

FIGURE 6 | Saturated adsorption capacities (A), effect of pH (B), adsorption kinetics (C), and adsorption isotherms for Hg(II) onto PPTA-AM samples (D).

the maximum adsorption values for the $\mathrm{Hg}(\mathrm{II})$ onto PPTA$\mathrm{AM}$ samples appeared at $\mathrm{pH}=5.0$. At low $\mathrm{pH}, \mathrm{NH}_{2}$, and $\mathrm{SH}$ on the surface of adsorbents were positively charged owing to protonation, thus the adsorption was dominated by electrostatic repulsion and disfavored. Moreover, the existence of a large amount of $\mathrm{H}^{+}$in the solution may compete adsorption with $\mathrm{Hg}(\mathrm{II})$. With the increase of $\mathrm{pH}$, the electrostatic repulsion between PPTA-AM and $\mathrm{Hg}$ (II) reduced for deprotonation and the deprotonated $\mathrm{NH}_{2}$ and $\mathrm{SH}$ can effectively coordinate with $\mathrm{Hg}$ (II), thus the adsorption capacity of PPTA-AM for $\mathrm{Hg}$ (II) increased ( $\mathrm{Ma}$ et al., 2017). The uptake of $\mathrm{Hg}$ (II) beyond pH 5.0 is decreased, which might attribute the formation of metal hydroxide species such as soluble $\mathrm{Hg}(\mathrm{OH})^{+}$. Therefore, the optimum value $\mathrm{pH}=5.0$ was chosen in the subsequent experiments. This value was the same for PPTA-A and PPTA-M, implying that the interaction of $\mathrm{NH}_{2}$ and $\mathrm{SH}$ did not affect the optimum $\mathrm{pH}$ values.

\section{Adsorption Kinetics and Adsorption Isotherms}

The adsorption kinetics for $\mathrm{Hg}$ (II) of PPTA-AM were determined to investigate the adsorption behavior and the results are shown in Figure 6C. As shown in Figure 6C, the adsorption for $\mathrm{Hg}$ (II) of PPTA-AM samples that reached equilibrium required a minimum of $6 \mathrm{~h}$. The experimental data were tested by using to Pseudo-first-order (Barkat et al., 2009) and pseudo-secondorder (Ho et al., 2000) models and the adsorption kinetic process were thus elucidated. The adsorption kinetics for $\mathrm{Hg}$ (II) of PPTA-AM were better described by pseudo-second-order model and equilibrium required a minimum within $6 \mathrm{~h}$ as shown in Figure 6B. The adsorption rate and adsorption capacities of PPTA-AM-70 were maximum, due to porous structure and to proceed the bicontinuum process, which occurred either in series or in parallel, being the more common bicontinuum conceptualization (Brusseau et al., 1989).

The pseudo-first-order and pseudo-second order models are, respectively, expressed by Equations (2) and (3).

$$
\begin{aligned}
\ln \left(q_{e}-q_{t}\right) & =\ln q_{e}-k_{1} t \\
\frac{t}{q_{t}} & =\frac{1}{k_{2} q_{e}^{2}}+\frac{t}{q_{e}}
\end{aligned}
$$

$q_{\mathrm{e}}$ and $q_{\mathrm{t}}\left(\mathrm{mmol} \mathrm{g}^{-1}\right)$ are the adsorption amounts of $\mathrm{Hg}(\mathrm{II})$ at equilibrium and time $t$ ( $\mathrm{min})$, respectively. $k_{1}$ and $k_{2}$ are the rate constants of pseudo-first-order $\left(\mathrm{h}^{-1}\right)$ and pseudo-second-order $\left(\mathrm{g} \mathrm{mmol}^{-1} \mathrm{~h}^{-1}\right.$ ) adsorption. The experimental and calculated $q_{\mathrm{e}}$ 
values, rate constants and regression coefficient $\left(R^{2}\right)$ values are all presented in Table 3.

As shown in Table 3, the adsorption process followed the pseudo-second-order model well and had better correlation coefficients than the pseudo-first-order model for samples. Therefore, the adsorption kinetics of $\mathrm{Hg}$ (II) onto the adsorbents was better described by pseudo-second-order model.

The isotherm adsorption of PPTA-AM for $\mathrm{Hg}(\mathrm{II})$ was investigated and the results are shown in Figure 6D. The Langmuir and Freundlich equations were adopted to fit the experimental data. The linear expressions of Langmuir and Freundlich models can be written as Equations (4) and (5) (Zhang et al., 2015):

$$
\begin{aligned}
\frac{C_{e}}{q_{e}} & =\frac{C_{e}}{q}+\frac{1}{q K_{L}} \\
\ln q_{e} & =\ln K_{F}+\frac{\ln C_{e}}{n}
\end{aligned}
$$

where $q_{\mathrm{e}}$ is the equilibrium concentration of $\mathrm{Hg}(\mathrm{II})$ on the adsorbent $\left(\mathrm{mg} \mathrm{g}^{-1}\right), C_{e}$ is the equilibrium concentration of $\mathrm{Hg}(\mathrm{II})$ in solution $\left(\mathrm{mg} \mathrm{L}^{-1}\right), q$ is the maximum capacity of adsorbent $\left(\mathrm{mg} \mathrm{g}^{-1}\right)$, and $K_{\mathrm{L}}$ is the Langmuir adsorption constant $\left(\mathrm{L} \mathrm{mg}^{-1}\right) . K_{\mathrm{F}}$ is the binding energy constant reflecting the affinity of the adsorbents to metal ions; $n$ is the Freundlich exponent related to adsorption intensity.

The corresponding Langmuir and Freundlich constants and correlation coefficients $\left(\mathrm{R}^{2}\right)$ are listed in Table 4 . From the correlation coefficients in Table 4, it can be concluded that the experiment data fitted Langmuir equation better than Freundlich equation, revealing the adsorption of $\mathrm{Hg}(\mathrm{II})$ adsorption on PPTA-AM obeyed the Langmuir adsorption isotherm. This implies that the adsorption of $\mathrm{Hg}(\mathrm{II})$ on PPTA-AM followed the mechanism of monolayer adsorption (chemisorption) (Qu et al., 2013).

Based on the $q_{\text {the }}$ values in Table 4, these values have a significant advantage over other silica adsorption materials, e.g., silica-dithizone at $0.22 \mathrm{mmol} \mathrm{g}^{-1}$ (Cestari et al., 2004), and pure functionalized polysilsesquioxane, e.g., diethylenetriaminebridged polysilsesquioxanes at $1.81 \mathrm{mmol} \mathrm{g}^{-1}$ (Sun et al., 2014), POSS-SH at $0.06 \mathrm{mmol} \mathrm{g}^{-1}$ (Wang et al., 2014). They are

\begin{tabular}{|c|c|c|c|}
\hline System & Mental ions & $q\left(\mathrm{mmol} \mathrm{g}^{-1}\right)$ & Selectivity coefficient* \\
\hline \multirow[t]{2}{*}{$\mathrm{Hg}(I I)-\mathrm{Pb}(I I)$} & $\mathrm{Hg}(\mathrm{II})$ & 1.36 & $\infty$ \\
\hline & $\mathrm{Pb}(I I)$ & 0.00 & \\
\hline \multirow[t]{2}{*}{$\mathrm{Hg}(I I)-\mathrm{Cu}(I I)$} & $\mathrm{Hg}(\mathrm{II})$ & 1.35 & $\infty$ \\
\hline & $\mathrm{Cu}(\mathrm{II})$ & 0.00 & \\
\hline \multirow[t]{2}{*}{$\mathrm{Hg}(\mathrm{II})-\mathrm{Ni}(\mathrm{II})$} & $\mathrm{Hg}(I I)$ & 1.36 & $\infty$ \\
\hline & $\mathrm{Ni}(I I)$ & 0.00 & \\
\hline \multirow[t]{2}{*}{$\mathrm{Hg}(I I)-\mathrm{Cd}(I I)$} & $\mathrm{Hg}(I I)$ & 1.36 & $\infty$ \\
\hline & $\mathrm{Zn}(I I)$ & 0.00 & \\
\hline \multirow[t]{2}{*}{$\mathrm{Hg}(I I)-\mathrm{Ag}(I)$} & $\mathrm{Hg}(I I)$ & 1.31 & 10 \\
\hline & $\mathrm{Ag}(\mathrm{I})$ & 0.13 & \\
\hline
\end{tabular}

TABLE 5 | Adsorption selectivity of PPTA-AM-70 toward $\mathrm{Hg}(\mathrm{II})$ at $25^{\circ} \mathrm{C}(\mathrm{pH} 5.0)$.

"The selective coefficient was the ratio of adsorption capacities of metal ions in a binary system.

\begin{tabular}{|c|c|c|c|c|c|c|c|}
\hline \multirow[t]{2}{*}{ Adsorbents } & \multirow{2}{*}{$\begin{array}{c}q_{\exp } \\
\left(\mathrm{mmol} \mathrm{g}^{-1}\right)\end{array}$} & \multicolumn{3}{|c|}{ Pseudo-first-order kinetics } & \multicolumn{3}{|c|}{ Pseudo-second-order kinetics } \\
\hline & & $\begin{array}{c}k_{1} \\
\left(h^{-1}\right)\end{array}$ & $\begin{array}{c}q_{e(c a l)} \\
\left(\mathrm{mmol} \mathrm{g}^{-1}\right)\end{array}$ & $R_{1}^{2}$ & $\frac{k_{2}}{\left(\mathrm{~g} \mathrm{mmol}^{-1} \mathrm{~h}^{-1}\right)}$ & $\begin{array}{c}q_{e} \\
\left(\mathrm{mmol} \mathrm{g}^{-1}\right)\end{array}$ & $R_{2}^{2}$ \\
\hline PPTA-AM-90 & 1.125 & 0.156 & 0.858 & 0.9412 & 1.579 & 1.118 & 0.9972 \\
\hline PPTA-AM-70 & 1.365 & 0.197 & 1.154 & 0.9695 & 1.891 & 1.356 & 0.9973 \\
\hline PPTA-AM-50 & 1.315 & 0.183 & 0.109 & 0.9754 & 1.645 & 1.321 & 0.9975 \\
\hline PPTA-AM-30 & 1.216 & 0.173 & 0.965 & 0.9855 & 1.441 & 1.210 & 0.9973 \\
\hline PPTA-AM-10 & 1.186 & 0.160 & 0.956 & 0.9653 & 1.370 & 1.185 & 0.9962 \\
\hline
\end{tabular}

TABLE 3 | Kinetic parameters for the adsorption of $\mathrm{Hg}(\mathrm{II})$ on PPTA-AM samples.

\begin{tabular}{|c|c|c|c|c|c|c|c|}
\hline \multirow[t]{2}{*}{ Adsorbents } & \multicolumn{3}{|c|}{ Langmuir } & \multicolumn{3}{|c|}{ Freundlich } & \multirow{2}{*}{$\begin{array}{c}\begin{array}{l}\text { Ratio of functional } \\
\text { group to metal ion* }\end{array} \\
\left(\mathrm{NH}_{2}+\mathrm{SH}\right) / \mathrm{Hg}(\mathrm{II})\end{array}$} \\
\hline & $\begin{array}{c}q_{\text {the }} \\
\left(\mathrm{mmol} \mathrm{g}^{-1}\right)\end{array}$ & $\begin{array}{c}K_{\mathrm{L}} \\
\left(\mathrm{L} \mathrm{mmol}^{-1}\right)\end{array}$ & $R_{L}^{2}$ & $\begin{array}{c}K_{F} \\
\left(\mathrm{mmol} \mathrm{g}^{-1}\right)\end{array}$ & $n$ & $R_{F}^{2}$ & \\
\hline PPTA-AM-90 & 1.32 & 1.42 & 0.9982 & 0.051 & 1.80 & 0.9802 & 1.36 \\
\hline PPTA-AM-70 & 1.54 & 0.41 & 0.9961 & 0.10 & 2.42 & 0.9775 & 1.25 \\
\hline PPTA-AM-50 & 1.41 & 0.43 & 0.9914 & 0.11 & 1.98 & 0.9682 & 1.42 \\
\hline PPTA-AM-30 & 1.34 & 0.45 & 0.9912 & 0.15 & 1.68 & 0.9743 & 1.49 \\
\hline PPTA-AM-10 & 1.33 & 0.54 & 0.9941 & 0.041 & 1.57 & 0.9891 & 1.42 \\
\hline
\end{tabular}

TABLE 4 | Langmuir and Freundlich isotherm constants for the adsorption of $\mathrm{Hg}$ (II) on PPTA-AM at $25^{\circ} \mathrm{C}(\mathrm{pH} 5.0)$.

*The Ratio of functional group to metal ion is equal to M/q; wherein, M presents the amount of functional group (NH $2+S H)$ in PPTA-AM (Table 1). 
also higher than those of the monofuctional polysilsesquioxanes coated PPTA fibers, e.g., PPTA-A at $10.64 \mathrm{mmol} \mathrm{g}^{-1}$ and PPTA$\mathrm{M}$ at $10.22 \mathrm{mmol} \mathrm{g}^{-1}$ (Wang et al., 2017). This implies that PPTA-AM with amino- and thiol- bifunctional groups possessed higher functional group utilization rates of polysilsesquioxanes than PPTA-A and PPTA-M adsorbents with amino- or thiolmonofunctional groups.

\section{Adsorption Selectivity}

The adsorption selectivities of PPTA-AM-70 were chosen as representatives in binary ion systems to compare the differences in adsorption properties between adsorbents with bifunctional groups and those with monofunctional groups. The results are presented in Table 5. From Table 5, it was found that PPTA-AM-70 exhibited excellent selectivity toward $\mathrm{Hg}(\mathrm{II})$ in the presence of $\mathrm{Pb}(\mathrm{II}), \mathrm{Cu}(\mathrm{II}), \mathrm{Ni}(\mathrm{II})$, and $\mathrm{Cd}(\mathrm{II})$, implying that bifunctionalization had no significant effect on its adsorption selectivity.

\section{Adsorption Mechanism}

The adsorption mechanism of PPTA-AM for $\mathrm{Hg}$ (II) using the XPS technique by comparing the changes of binding energies of $\mathrm{N}_{1 \mathrm{~s}}, \mathrm{~S}_{2 \mathrm{p}}$, and $\mathrm{Hg}_{4 \mathrm{f}}$ before and after adsorption. Figure 7 shows the $\mathrm{N}_{1 \mathrm{~s}}, \mathrm{~S}_{2 \mathrm{p}}$, and $\mathrm{Hg}_{4 \mathrm{f}}$ spectra of PPTA-AM-70 after adsorbing $\mathrm{Hg}(\mathrm{II})$. From Figure 7, it can be found that the binding energies of $\mathrm{N}_{1 \mathrm{~s}}$ in $\mathrm{NH}_{2}$ and $\mathrm{S}_{2 \mathrm{p}}$ in $\mathrm{SH}$ in PPTA-AM-70 were shifted from 399.03 to $399.68 \mathrm{eV}$ and from 164.12 to $164.32 \mathrm{eV}$, respectively, while that of $\mathrm{Hg}_{4 \mathrm{f}}$ was shifted from 104.00 to $101.98 \mathrm{eV}$ after adsorption, implying that both $\mathrm{NH}_{2}$ and $\mathrm{SH}$ were involved in the coordination with $\mathrm{Hg}(\mathrm{II})$. The binding energy of $\mathrm{N}_{1 \mathrm{~s}}$ of amide $400.18 \mathrm{eV}$ in PPTA-AM-70 had no change before and after adsorption, indicating that $\mathrm{N}$ of amide was not involved in adsorption process. The binding energy of $S_{2 p}$ at $168.32 \mathrm{eV}$ implied that there was a certain degree of redox reaction in the adsorption process (Qu et al., 2006).

According to the data in Table 4, the coordination ratio of $\left(\mathrm{NH}_{2}+\mathrm{SH}\right)$ to $\mathrm{Hg}(\mathrm{II})$ of PPTA-AM samples can be calculated to be $1.36,1.25,1.42,1.49$, and 1.42 , respectively, which were much lower than 2.4-2.89 of $\mathrm{NH}_{2} / \mathrm{Hg}$ (II) for PPTA-A and 2.563.96 of $\mathrm{SH} / \mathrm{Hg}$ (II) for PPTA-M ones. This suggested that PPTAAM adsorbents needed only $1.25-1.49\left(\mathrm{NH}_{2}+\mathrm{SH}\right)$ to chelate one $\mathrm{Hg}$ (II) ion. In other words, the bifunctional adsorbents prepared by the DRSF method had higher functional group utilization than those with monofunctional groups. This may be a result of their unique loose open meso- or macroporous features of PAMPAQ. Based on the above analysis, the adsorption mechanism of the PPTA-AM samples is proposed as illustrated in Scheme 2. The structures of chelates depended on the proportion of $\mathrm{NH}_{2}$ and $\mathrm{SH}$ in PAMPSQ. When the proportion of $\mathrm{NH}_{2}$ was greater than $\mathrm{SH}$, the structure was dominated by I, II and IV. When the proportion

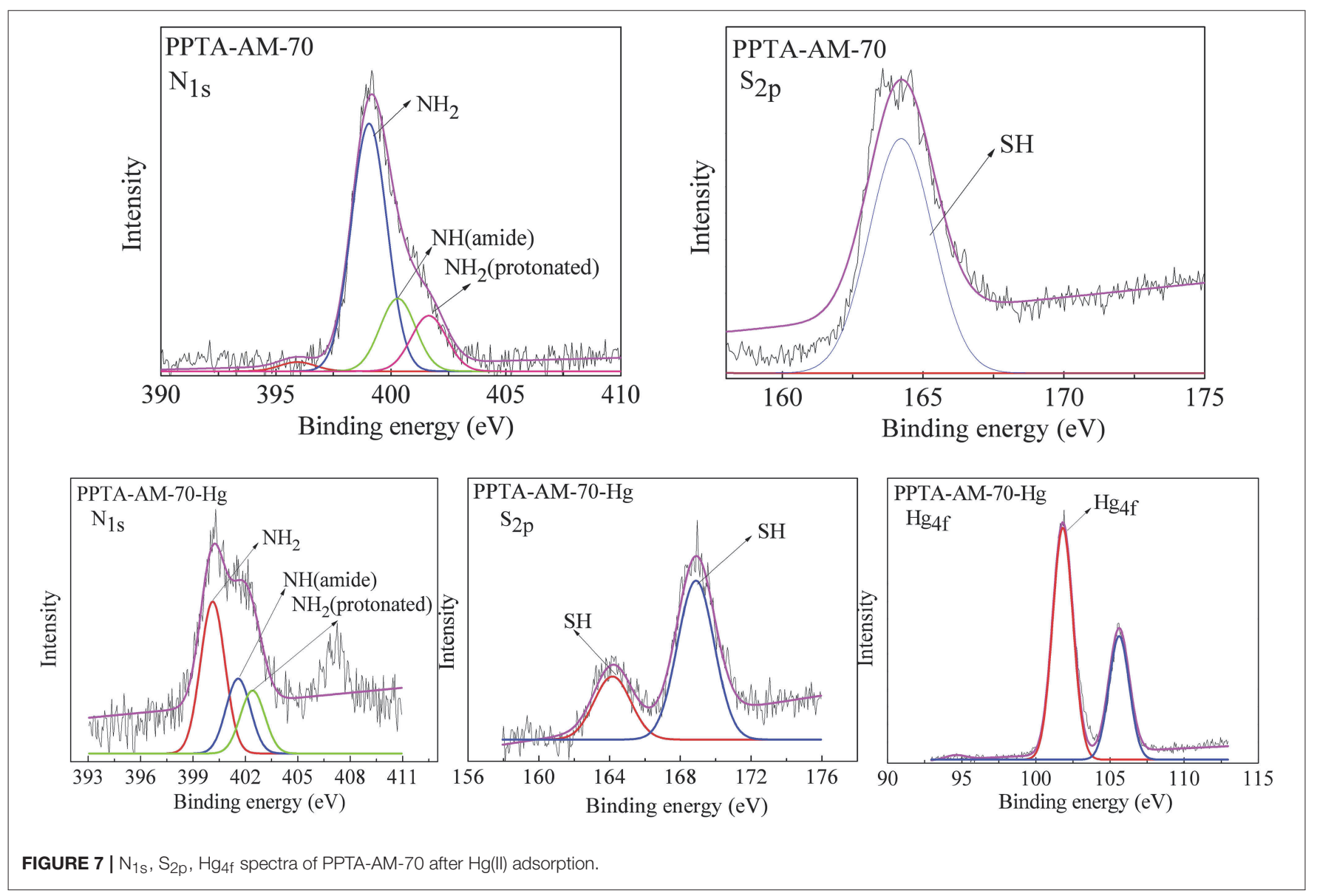




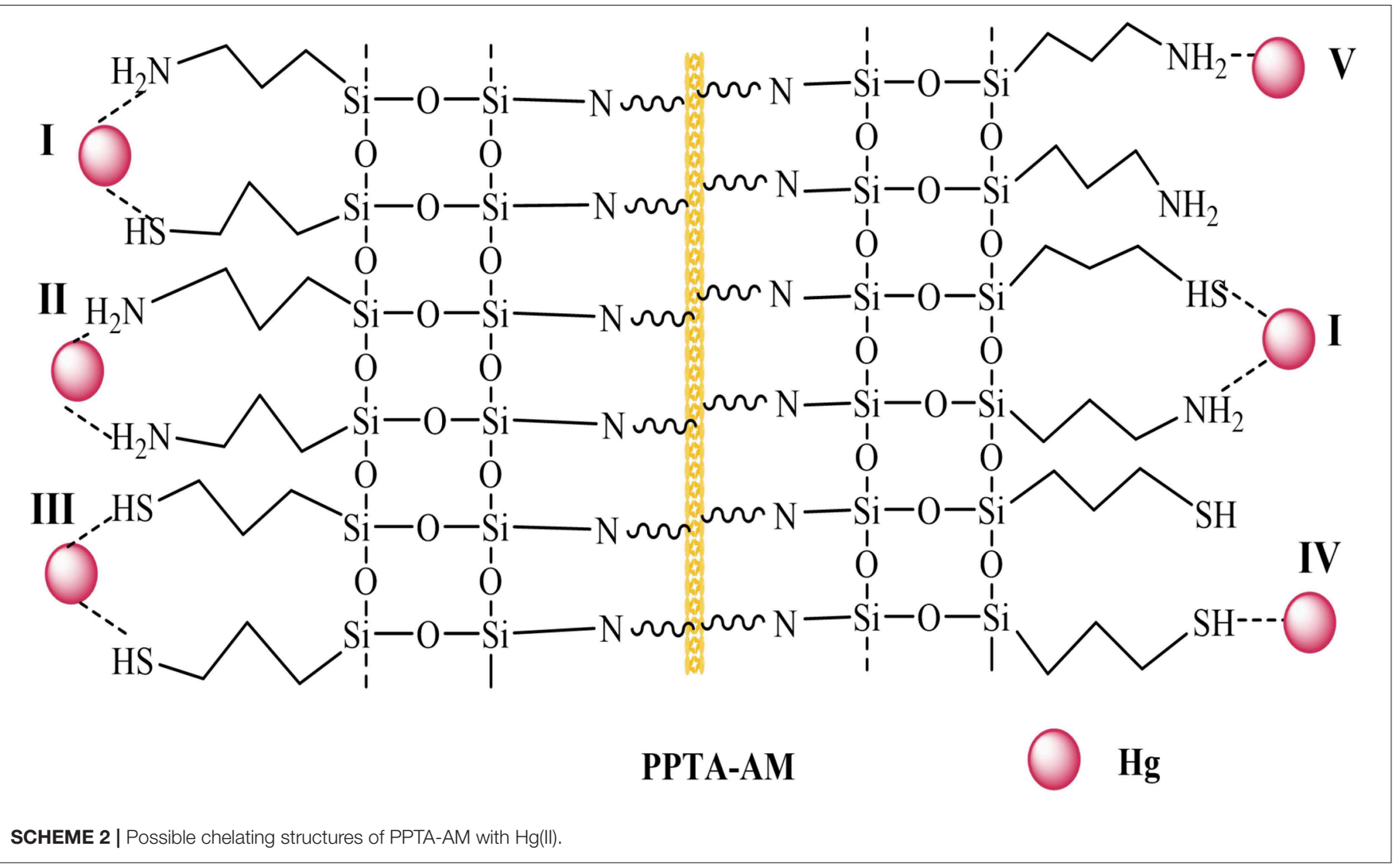

of $\mathrm{NH}_{2}$ was lower than $\mathrm{SH}$, the structure was dominated by $\mathrm{I}$, III, and V. When the proportion of $\mathrm{NH}_{2}$ was equal to $\mathrm{SH}$, the structure was dominated by I, IV, and V.

\section{Regeneration}

PPTA-AM-70 was chosen as a representative to test the reusability. The elution rate was over $95 \%$ eluted by the eluent system of $4 \%$ thiourea in $0.5 \mathrm{M} \mathrm{HCl}$. Thiourea in $\mathrm{HCl}$ is frequently used for the desorption of $\mathrm{Hg}$ (II) from adsorbent surfaces because the sulfur and nitrogen present in thiourea can form a coordination interaction with $\mathrm{Hg}$ (II) ions, and because thiourea dissolved in $\mathrm{HCl}$ is expected to have more of a desorption effect (Velempini et al., 2019). Five cycles of adsorption-desorption were carried out on a single adsorbent sample and the results are shown in Table 6. As can be seen from Table 6, the adsorption properties of PPTA-AM-70 had only a small decrease after five cycles of adsorption-desorption, with the uptake all being above $90 \%$. Therefore, the adsorbent was suitable for repeated use at a diminishing rate in the adsorption capacity.

\section{CONCLUSION}

Bifunctional adsorbents PPTA-AM, amino- and thiolpolysilsesquioxane (PAMPSQ) simultaneously coated poly( $p$-phenylenetherephthal amide) fibers were successfully prepared by developed DRSF method. The loose and meso-
TABLE 6 | Regeneration properties of PPTA-AM-70 for Hg(II) adsorption.

\begin{tabular}{lcc}
\hline Regeneration times & $\mathbf{Q}_{\mathbf{e}}\left(\mathbf{m m o l ~}^{\mathbf{- 1}}\right)$ & Desorption rate (\%) \\
\hline 1 & 1.365 & 94.52 \\
2 & 1.355 & 93.53 \\
3 & 1.341 & 92.23 \\
4 & 1.325 & 90.56 \\
5 & 1.306 & 90.55 \\
\hline
\end{tabular}

or macro-porous structures of PAMPSQs in the form of nanoparticles were formed on the surface of PPTA fibers. The morphologies of the PAMPSQ coatings were dependent on the the proportion of reactants of APTES and MPTES. PPTA-AM adsorbents just need 1.25-1.49 $\mathrm{NH}_{2}+\mathrm{SH}$ chelate one $\mathrm{Hg}(\mathrm{II})$ ion, indicating that the PAMPSQ coating in these bifunctionals adsorbents had much higher functional group utilization than pure functionalized polysilsesquioxane adsorption materials, and the corresponding monofunctional polysilsesquioxane coated PPTA fibrous adsorbents for $\mathrm{Hg}$ (II) adsorption.

\section{DATA AVAILABILITY}

The datasets generated for this study are available on request to the corresponding author. 


\section{AUTHOR CONTRIBUTIONS}

RQ: work design. YW: data collection and organize the draft. YM, $\mathrm{KA}, \mathrm{XJ}$, and YuZ: data collection. CS and CJ: characterization. YiZ: make important changes to the paper.

\section{REFERENCES}

Acres, R. G., Ellis, A. V., Alvino, J., Lenahan, C. E., Khodakov, D. A., Metha, G. F., et al. (2012). Molecular structure of 3aminopropyltriethoxysilane layersformed on silanol-terminated silicon surfaces. J. Phys. Chem C 116, 6289-6297. doi: 10.1021/jp2 $12056 \mathrm{~s}$

Adam, F., Appaturi, J. N., Thankappan, R., and Nawi, M. A. M. (2010). Silica-tin nanotubes prepared from rice husk ash by sol-gel method: characterization and its photocatalytic activity. Appl. Surf. Sci. 257, 811-816. doi: 10.1016/j.apsusc.2010.07.070

Ahmed, A. E., and Adam, F. (2007). Indium incorporated silica from rice husk and its catalytic activity. Micropor. Mesopor. Mater. 103, 284-295. doi: 10.1016/j.micromeso.2007.01.055

Barkat, M., Nibou, D., Chegrouche, S., and Mellah, A. (2009). Kinetics and thermodynamics studies of chromium(VI) ions adsorption onto activated carbon from aqueous solutions. Chem. Eng. Process. 48, 38-47. doi: 10.1016/j.cep.2007.10.004

Basso, M. C., Cerrella, E. G., and Cukierman, A. L. (2002). Activated carbons developed from a rapidly renewable biosource for removal of cadmium(II) and. nickel(II) from dilute aqueous solutions. Ind. Eng Chem. Res. 41, 180-189. doi: 10.1021/ie010664x

Brusseau, M. L., Rao, P. S. C., and Gillham, R. W. (1989). Sorption non-ideality during organic contaminant transport in porous media. CRC Crit. Rev. Environ. Control 19, 33-99. doi: 10.1080/106433889093 88358

Cestari, A. R., Vieira, E. F. S., Lopes, E. C. N., and Silva, R. G. D. (2004). Kinetics and equilibrium parameters of $\mathrm{Hg}(\mathrm{II})$ adsorption on silica-dithizone. J. Colloid. Interf. Sci. 272, 271-276. doi: 10.1016/j.jcis.200 3.09.019

Giordani, S., Colomer, J. F., Cattaruzza, F., Alfonsi, J., and Meneghetti, M. (2009). Multifunctional hybrid materials composed of fullerene-based functionalized-single-walled carbon nanotubes. Carbon 47, 578-588. doi: 10.1016/j.carbon.2008.10.036

Gomez-Salazar, S., Lee, J. S., Heydweiller, J. C., and Tavlarides, L. L. S. (2003). Analysis of cadmium adsorption on novel organo-ceramic adsorbents with a thiol functionality. Ind. Eng. Chem. Res. 42, 3403-3412. doi: 10.1021/ie0 20840h

Ho, Y. S., McKay, G. J., Wase, D. A., and Foster, C. F. (2000). Study of the sorption of divalent metal ions on to peat. Adsorpt. Sci. Technol. 18, 639-650. doi: 10.1260/0263617001493693

Hua, M., Zhang, S., Pan, B., Zhang, W., Lv, L., and Zhang, Q. (2012). Heavy metal removal from water/wastewater by nanosized metal oxides: a review. J. Hazard. Mater. 211-212, 317-331. doi: 10.1016/j.jhazmat.201 1.10 .016

Huang, C. P., Chung, Y. C., and Liou, M. R. (1996). Adsorption of Cu(II) and $\mathrm{Ni}(\mathrm{II})$ by pelletized biopolymer. J. Hazard. Mater. 45, 265-277. doi: 10.1016/0304-3894(95)00096-8

Kropman, B. L., Blank, D. H. A., and Rogalla, H. (1997). Self-assembled monolayers of alkylsiloxanes on $\mathrm{SrTiO}_{3}$ substrates. Supramol. Chem. 4, 59-65. doi: 10.1016/S0968-5677(96)00043-0

Li, B., Li, X. H., Zhang, K. Q., Li, H., Zhao, Y. H., Ren, L. H., et al. (2015). Synthesis of POSS containing fluorosilicone block copolymers via RAFT polymerization for application as non-wetting coating materials. Prog. Org. Coat. 78, 88-199. doi: 10.1016/j.porgcoat.2014.09.004

Li, G., Zhao, Z., Liu, J., and Jiang, G. (2011). Effective heavy metal removal from aqueous systems by thiol functionalized magnetic mesoporous silica. J. Hazard. Mater. 192, 277-283. doi: 10.1016/j.jhazmat.2011.05.015

\section{ACKNOWLEDGMENTS}

We are grateful for the financial support by the National Natural Science Foundation of China (Grant No. 51673089, 51373074, 51073075, 51302127, 51143006).

Liu, T. M., Zheng, Y. S., and Hu, J. (2011). Surface modification of aramid fibers with novel chemical approach. Polym. Bull. 66, 259-275. doi: 10.1007/s00289-010-0313-y

Ma, Y. X., Xing, D., Shao, W. J., Du, X. Y., and La, P. Q. (2017). Preparation of polyamidoamine dendrimers functionalized magnetic graphene oxide for the adsorption of $\mathrm{Hg}(\mathrm{II})$ in aqueous solution. J. Colloid Interf. Sci. 505, 352-363. doi: 10.1016/j.jcis.2017.05.104

Majumder, S., Priyadarshini, M., Subudhi, U., Chainy, G. B. N., and Varma, S. (2009). X-ray photoelectron spectroscopic investigations of modifications in plasmid DNA after interaction with $\mathrm{Hg}$ nanoparticles. Appl. Surf. Sci. 256:438-442. doi: 10.1016/j.apsusc.2009.06.097

Mehdipouratae, S., Mosslemin, M. H., Kholghi, S., and Mohaghegh, S. M. S. (2013). Soluble, thermally stable poly(amide-ester)s containing pyridine pendent group. e-Polymers 9, 527-537. doi: 10.1515/epoly.200 9.9.1.527

Metwalli, E., Haines, D., Becker, O., Conzone, S., and Pantano, C. G. (2006). Surface characterizations of mono-, di-, and tri-aminosilane treated glass substrates. J. Colloid Interf. Sci. 298, 825-831. doi: 10.1016/j.jcis.200 6.03.045

Qiao, B., Wang, T. J., Gao, H., and Jin, Y. (2015). High density silanization of nano-silica particles using c-aminopropyltriethoxysilane (APTES). Appl. Surf. Sci. 351, 646-654. doi: 10.1016/j.apsusc.2015.05.174

Qu, R. J., Sun, C. M., Ji, C. N., Xu, Q., Wang, C. H., and Cheng, G. X. (2006). The sorption mechanism of $\mathrm{Au}(\mathrm{III})$ on sulfur-containing chelating resin poly[4-vinylbenzyl (2-hydroxyethyl) sulfide. Eur. Polym. J. 42, 254-258. doi: 10.1016/j.eurpolymj.2005.07.001

Qu, R. J., Zhang, Y., Qu, W. W., Sun, C. M., Chen, J., Ping, Y., et al. (2013). Mercury adsorption by sulfur- and amidoxime-containing bifunctional silica gel based hybrid materials. Chem. Eng. J. 219, 51-61. doi: 10.1016/j.cej.201 2.12.070

Sun, C. M., Li, C. X., Qu, R. J., Zhang, Y., Zhang, B. D., and Kuang, Y. Z. (2014). Syntheses of diethylenetriamine-bridged poly-silsesquioxanes and their structure-adsorption properties for $\mathrm{Hg}(\mathrm{II})$ and $\mathrm{Ag}(\mathrm{I})$. Chem. Eng. J. 240, 369-378. doi: 10.1016/j.cej.2013.11.092

Velempini, T., Pillay, K., Mbianda, X. Y., and Arotiba, O. A. (2019). Carboxymethyl cellulose thiol-imprinted polymers: synthesis, characterization and selective $\mathrm{Hg}$ (II) adsorption. J. Environ. Sci. 79, 280-296. doi: 10.1016/j.jes.201 8.11 .022

Wang, W. J., Chen, M. L., Chen, X. W., and Wang, J. H. (2014). Thiol-rich polyhedral oligomeric silsesquioxane as a novel adsorbent for mercury adsorption and specification. Chem. Eng. J. 242, 62-68. doi: 10.1016/j.cej.2013.12.063

Wang, Y. F., Qu, R. J., Pan, F. W., Jia, X. H., Sun, C. M., Ji, C. N., et al. (2017). Preparation and characterization of thiol- and amino-functionalized polysilsesquioxane coated poly(p-phenylenetherephthal amide) fibers and their adsorption properties towards $\mathrm{Hg}(\mathrm{II})$. Chem. Eng. J. 317,187-203. doi: 10.1016/j.cej.2017.02.073

Xu, C. Z., Qu, R. J., Li, S. S., Sun, C. M., Zhang, Y., Gao, J. J., et al. (2016). Preparation, characterization, and rapid adsorption of $\mathrm{Hg}^{2+}$ on nanoscale aramid-based adsorbent. J. Polym. Environ. 24, 206-220. doi: 10.1007/s10924-016-0764-9

Yang, M., Cao, K. Q., Sui, L., Qi, Y., Zhu, J., Waas, A., et al. (2011). Dispersions of aramid nanofibers: a new nanoscale building block. ACS. Nano 5, 6945-6954. doi: 10.1021/nn2014003

Zhang, H. P., Zhang, J. C., Chen, J. Y., Hao, X. M., Wang, S. Y., Feng, X. X., et al. (2006). Effects of solar UV irradiation on the tensile properties and structure of PPTA fiber. Polym. Degrad. Stab. 91, 2761-2767. doi: $10.1016 /$ j.polymdegradstab.2006.03.025 
Zhang, Y., Qu, R. J., Sun, C. M., Ji, C. N., Chen, H., and Yin, P. (2015). Improved synthesis of silica-gel-based dendrimer-like highly branched polymer as the $\mathrm{Au}(\mathrm{III})$ adsorbents. Chem. Eng. J. 270, 110-121. doi: 10.1016/j.cej.201 5.02 .006

Zhao, B., Song, J., Fang, T., Liu, P., Jiao, Z., Zhang, H. J., et al. (2012). Hydrothermal method to prepare porous NiO nanosheet. Mater. Lett. 67, 24-27. doi: 10.1016/j.matlet.2011.09.057

Zub, Y. L., Stolyarchuk, N. V., Chuiko, A. A., Dabrowski, A., and Barczak, M. (2005). New adsorbents based on bridged polysilsesquioxanes containing 3-mercaptopropyl functional groups. Mendeleev. Commun. 15, 168-170. doi: 10.1070/MC2005v015n04ABEH002096
Conflict of Interest Statement: The authors declare that the research was conducted in the absence of any commercial or financial relationships that could be construed as a potential conflict of interest.

Copyright (c) 2019 Wang, Qu, Mu, Sun, Ji, Zhang, An, Jia and Zhang. This is an open-access article distributed under the terms of the Creative Commons Attribution License (CC BY). The use, distribution or reproduction in other forums is permitted, provided the original author(s) and the copyright owner(s) are credited and that the original publication in this journal is cited, in accordance with accepted academic practice. No use, distribution or reproduction is permitted which does not comply with these terms. 